THE WABASH CENTER

JOURNAL oN TEACHING

\author{
Reviewed By \\ Barbara Thiede \\ University of North Carolina \\ Charlotte
}

BOOK REVIEW

\section{Rape Culture and Religious Studies}

\author{
Rhiannon Graybill, Meredith Minister, \\ and Beatrice Lawrence, editors \\ Lanham, MD: Lexington Books, 2019 \\ (vii + 207 pages, ISBN 978-1-4985-6284-3,\$95.00)
}

regularly engage with class, gender, race, sexuality, and ability, classroom conversations are often detached from the rape culture that surrounds them. The \#MeToo movement and the withdrawal of Obama-era guidance documents on Title IX and sexual violence have galvanized a public conversation that has not, the editors suggest, found purchase in religious studies classrooms.

Rape Culture and Religious Studies acknowledges that rape culture and sexualized violence is part and parcel of religious traditions. Survivors are sitting in religious studies classrooms, many of whom belong to religious traditions that promote or, at least, make a home for sexual violence. The editors therefore sought to create a volume that would do more than critique the lack of connectivity between religious studies and rape culture; they hoped to offer readers "real-life pedagogical reflections and tactics" (9).

Indeed, teachers in the field will find provocative material in this volume, which will help them rethink and reframe their course content. While not every essay is as trenchant or ground-breaking as one might hope, many are. Several contributors demonstrate how academic analysis of both ancient and emerging sacred texts can be brought into conversation with rape culture. Their essays explore a range of traditions and a variety of sources-often with innovative results. Can the well-known gang rape of the Levite's concubine in Judges 19 be understood as an ancient version of contemporary non-consensual pornography? Does the popular comic Priya's Shakti, a text that reformulates Hindu mythology in the struggle against gender-based violence, invite a critique of existing political structure not in its own pages, but because of the way women have publicly responded to its call to "speak without shame"? How does a layered, step-by-step approach to Deuteronomist texts on genocide, slavery, and rape permit students to name how the Bible justifies violence-even in their time? What might students conclude about the intersections of religious texts and traditions with contemporary rape culture as a result?

Rape Culture and Religious Studies defines and contextualizes key issues critical for both teachers and students. Meredith Minister exposes the ways in which the binary of rape and consensual sex relies on myths of self-control and bodily autonomy, fetishizing verbal communication and ignoring the fact that consent, too, involves power dynamics. Rhiannon Graybill calls for teachers to nuance classroom conversations around harm, to uncover the relationship between race and sexual violence and colonialist visions of women as victims, and to acknowledge the ambiguities and ambivalence introduced by sexual pleasure.

Revealing the sexual violence inherent in religious traditions and offering students ways to name, analyze, and understand how this violence intersects with the rape culture that surrounds them is a pedagogical imperative in our time. Rape Culture and Religious Studies makes a significant contribution to that project. 